\title{
Timing of Allergenic Food Introduction to the Infant Diet and Risk of Allergic or Autoimmune Disease A Systematic Review and Meta-analysis
}

Despo lerodiakonou, MD, PhD; Vanessa Garcia-Larsen, PhD; Andrew Logan, PhD; Annabel Groome, BSc; Sergio Cunha, MD; Jennifer Chivinge, BSc; Zoe Robinson, BSc; Natalie Geoghegan, BSc; Katharine Jarrold, BSc; Tim Reeves, BSc; Nara Tagiyeva-Milne, PhD; Ulugbek Nurmatov, MD, PhD; Marialena Trivella, DPhil; Jo Leonardi-Bee, PhD; Robert J. Boyle, MD, PhD

IMPORTANCE Timing of introduction of allergenic foods to the infant diet may influence the risk of allergic or autoimmune disease, but the evidence for this has not been comprehensively synthesized.

OBJECTIVE To systematically review and meta-analyze evidence that timing of allergenic food introduction during infancy influences risk of allergic or autoimmune disease.

DATA SOURCES MEDLINE, EMBASE, Web of Science, CENTRAL, and LILACS databases were searched between January 1946 and March 2016.

STUDY SELECTION Intervention trials and observational studies that evaluated timing of allergenic food introduction during the first year of life and reported allergic or autoimmune disease or allergic sensitization were included.

DATA EXTRACTION AND SYNTHESIS Data were extracted in duplicate and synthesized for meta-analysis using generic inverse variance or Mantel-Haenszel methods with a random-effects model. GRADE was used to assess the certainty of evidence.

MAIN OUTCOMES AND MEASURES Wheeze, eczema, allergic rhinitis, food allergy, allergic sensitization, type 1 diabetes mellitus, celiac disease, inflammatory bowel disease, autoimmune thyroid disease, and juvenile rheumatoid arthritis.

RESULTS Of 16289 original titles screened, data were extracted from 204 titles reporting 146 studies. There was moderate-certainty evidence from 5 trials (1915 participants) that early egg introduction at 4 to 6 months was associated with reduced egg allergy (risk ratio [RR], $0.56 ; 95 \% \mathrm{Cl}, 0.36-0.87 ; P^{2}=36 \% ; P=.009$ ). Absolute risk reduction for a population with $5.4 \%$ incidence of egg allergy was 24 cases ( $95 \% \mathrm{Cl}, 7-35$ cases) per 1000 population. There was moderate-certainty evidence from 2 trials (1550 participants) that early peanut introduction at 4 to 11 months was associated with reduced peanut allergy $(\mathrm{RR}, 0.29 ; 95 \% \mathrm{Cl}$, $0.11-0.74 ; I^{2}=66 \% ; P=.009$ ). Absolute risk reduction for a population with $2.5 \%$ incidence of peanut allergy was 18 cases $(95 \% \mathrm{Cl}, 6-22$ cases) per 1000 population. Certainty of evidence was downgraded because of imprecision of effect estimates and indirectness of the populations and interventions studied. Timing of egg or peanut introduction was not associated with risk of allergy to other foods. There was low- to very low-certainty evidence that early fish introduction was associated with reduced allergic sensitization and rhinitis. There was high-certainty evidence that timing of gluten introduction was not associated with celiac disease risk, and timing of allergenic food introduction was not associated with other outcomes.

CONCLUSIONS AND RELEVANCE In this systematic review, early egg or peanut introduction to the infant diet was associated with lower risk of developing egg or peanut allergy. These findings must be considered in the context of limitations in the primary studies.

JAMA. 2016;316(11):1181-1192. doi:10.1001/jama.2016.12623
Editorial page 1157

Supplemental content

CME Quiz at

jamanetworkcme.com
Author Affiliations: Section of Paediatrics, Imperial College London, London, England (lerodiakonou, Logan, Groome, Chivinge, Robinson, Geoghegan, Jarrold, Boyle); Respiratory Epidemiology, Imperial College London, London, England (lerodiakonou, Garcia-Larsen, Cunha, Reeves); Institute of Medical Sciences, University of Aberdeen, Aberdeen, Scotland (Tagiyeva-Milne); University Division of Population Medicine, Cardiff University, Cardiff, Wales (Nurmatov); Centre for Statistics in Medicine, University of Oxford, Oxford, England (Trivella); Division of Epidemiology and Public Health, University of Nottingham, Nottingham, England (Leonardi-Bee).

Corresponding Author: Robert J. Boyle, MD, PhD, Section of Paediatrics, Imperial College London, Norfolk Place, Wright Fleming Bldg, London W2 1PG, England (r.boyle@nhs.net). 
ncreasing attention has focused on the role of timing of introduction of allergenic food into the infant diet and risk of allergic and autoimmune diseases. Infant feeding guidelines have moved away from advising parents to delay the introduction of allergenic food, but most guidelines do not yet advise early feeding of such foods..$^{1-3}$ Several professional organizations have responded to recent research findings by issuing interim guidance advising early peanut introduction in infants at high risk of peanut allergy, with some caveats. ${ }^{4,5}$ However, a randomized clinical trial of early introduction of multiple allergenic foods did not show efficacy for preventing food allergy, ${ }^{6}$ and a trial of early gluten introduction showed no effect on risk of celiac disease. ${ }^{7}$ The implications for preventing food allergy or other immune-mediated health conditions in the general population are not clear.

To inform UK infant feeding guidance, we undertook a systematic review and meta-analysis for the UK Food Standards Agency, evaluating whether timing of allergenic food introduction to the infant diet influences risk of allergic or autoimmune disease. This is one of a series of systematic reviews of dietary exposures in pregnancy or infancy and immune outcomes, the first of which reviewed hydrolyzed infant formula. ${ }^{8}$ The immunological mechanisms underlying the different allergic and autoimmune diseases vary. For example, most food allergy is characterized by IgE-mediated inflammation, whereas type 1 diabetes mellitus is caused by T cell-mediated islet cell destruction. ${ }^{9,10}$ However, these diseases share a common feature of impaired immune tolerance, and immune function in infancy may be modified by dietary exposures. Therefore, a comprehensive range of allergic and autoimmune outcomes were included.

\section{Methods and Literature Search}

Methods are described in the Supplement. This systematic review is reported according to PRISMA guidance. ${ }^{11} \mathrm{We}$ searched the Cochrane Library, EMBASE, LILACS, MEDLINE, Web of Science, and http://apps.who.int/trialsearch from January 1, 1946, to March 8, 2016. Intervention trials and observational studies evaluating age at allergenic food introduction (milk, egg, fish, shellfish, tree nuts, wheat, peanuts, soya $)^{12}$ during the first year and allergic or autoimmune disease at any age were included. Other systematic reviews rated as high quality using published criteria ${ }^{13}$ were also included per the study protocol to avoid duplicating existing work. When other systematic reviews were included, original studies that were not captured by the other reviews were also summarized. Outcomes evaluated were wheeze, eczema, allergic rhinitis, food allergy (a reproducible hypersensitivity reaction to a food), allergic sensitization (the presence of specific IgE to an allergen), type 1 diabetes mellitus, celiac disease, inflammatory bowel disease, juvenile rheumatoid arthritis, psoriasis, and vitiligo.

Data were extracted in duplicate and risk of bias assessed using the Cochrane Risk of Bias tool and the National Institute for Clinical Excellence methodological checklists for intervention and observational studies, respectively. Publica-

\section{Key Points}

Question Does the timing of allergenic food introduction to infants affect their risk of developing allergic or autoimmune disease?

Findings There was moderate-certainty evidence that early introduction of egg (from 4-6 months) or peanut (from 4-11 months) was associated with reduced risk of egg or peanut allergy, respectively. There was low- to very low-certainty evidence that early fish introduction was associated with reduced allergic sensitization and rhinitis and high-certainty evidence that timing of gluten introduction was not associated with risk of celiac disease.

Meaning Early introduction of egg or peanut to infants was associated with a reduced risk of egg or peanut allergy.

tion bias was assessed using funnel plots and the Egger test when meta-analyses included at least 10 studies. Randomeffects meta-analyses used generic inverse variance and Mantel-Haenszel methods for observational and intervention studies, respectively. Heterogeneity was quantified using the $I^{2}$ statistic. Meta-analyses with $I^{2}>80 \%$ were not pooled. For meta-analyses with more than 5 studies, we explored heterogeneity in prespecified subgroup analyses of study design, risk of bias, risk of conflict of interest, and features of the population, intervention, and outcome assessment. For meta-analyses with 5 or fewer studies, we explored statistical heterogeneity descriptively and also conducted sensitivity analyses by study design and risk of bias for the key review findings. The statistical program used for meta-analysis was R, version 3.1.0 (R Project), and statistical significance was set at 2 -sided $P<.05$.

Post hoc trial sequential analysis was used to quantify statistical reliability of moderate- or high-certainty review findings using a 2 -sided $P<.05$ significance level, $80 \%$ power, and control event rates from included studies to estimate optimal heterogeneity-adjusted and unadjusted information sizes needed to identify relative risk reductions of $10 \%, 20 \%$, and $30 \%$. Trial sequential analysis quantifies statistical reliability of data in a cumulative meta-analysis in a similar way to an interim analysis in a single randomized clinical trial. GRADE was used to assess certainty of evidence, and the protocol was registered in PROSPERO.${ }^{14}$ Ethical approval was not required by the Imperial College Joint Research Office. The data set and statistical code are available from the corresponding author.

\section{Results}

Search results are summarized in eFigure 1 (existing systematic reviews) and eFigure 2 (original studies) in the Supplement. A summary of the findings of the 2 included systematic reviews is shown in eTables 1 and 2 in the Supplement.

Title, abstract, and full-text screening of original studies yielded 146 eligible studies (204 separate titles). Overall, 24 intervention trials (39 titles) evaluated allergic outcomes in 13298 participants and 5 intervention trials (6 titles) evaluated autoimmune diseases in 5623 participants. Sixty-nine 
observational studies (90 titles) reported allergic outcomes in 142103 participants and 48 observational studies (69 titles) evaluated autoimmune diseases in 63576 participants. No study reported psoriasis or vitiligo. For allergic outcomes, these included 55 cohort studies (1 retrospective), 2 nested case-control studies, and 12 case-control or cross-sectional studies. For autoimmune diseases, there were 7 cohort studies, 4 nested case-control studies, and 37 case-control studies. Characteristics of included studies are summarized in eTables 3 and 4 (allergic outcomes) and eTables 5 and 6 (autoimmune outcomes) in the Supplement. More detailed characteristics of the intervention studies of egg or peanut introduction that reported egg or peanut allergy are shown in Table 1 and Table 2.

Risk of bias was low in 4 (17\%) of 24 intervention trials and 29 (42\%) of 69 observational studies for allergic outcomes (eTables 7 and 8 in the Supplement), and in 1 (20\%) of 5 intervention trials and 10 (21\%) of 48 observational studies for autoimmune outcomes (eTables 9 and 10 in the Supplement). The main issues identified were attrition bias in intervention trials and lack of adjustment for potential confounders in observational studies.

The key findings of the systematic review are summarized in Table 3, with GRADE evidence assessment summarized in Table 4 and specific analyses for all positive or highcertainty findings shown in Figure 1, Figure 2, and Figure 3. More detailed methods and a summary of all findings are in eTable 11 in the Supplement. The full report with a detailed description of all findings including meta-analyses and detailed methods is available on the UK Food Standards Agency website (http://www.food.gov.uk/science/research /allergy-research/fs305005) together with an associated statement by the UK Committee on Toxicity of Chemicals in Food, Consumer Products and the Environment (http://cot .food.gov.uk/cotstatements).

\section{Risk of Food Allergy and Allergic Sensitization}

Fifteen intervention trials reported food allergy to any food or to milk, egg, or peanut separately in 10304 participants. Seventeen trials reported allergic sensitization to any allergen, aeroallergen, food allergen, egg, peanut, or milk in 7310 participants. A summary of findings is shown in eTable 11 in the Supplement. Key findings for food allergy and allergic sensitization to egg, peanut, or milk are summarized in Figure 1, A and B.

Meta-analysis of 5 trials (1915 participants) showed evidence that egg introduction at 4 to 6 months was associated with lower risk of egg allergy compared with later egg introduction (risk ratio [RR], 0.56; 95\% CI, 0.36-0.87; $P=.009$; moderate heterogeneity $\left.\left[I^{2}=36 \%\right]\right) .6,15-18$ Absolute risk reduction for a population with $5.4 \%$ incidence of egg allergy was 24 cases (95\% CI, 7-35 cases) per 1000 population. Meta-analysis of 4 trials (1786 participants) showed no association between timing of egg introduction and egg sensitization.

Meta-analysis of 2 trials (1550 participants) showed evidence that peanut introduction at age 4 to 11 months was associated with lower risk of peanut allergy (RR, 0.29; 95\% CI, 0.11-0.74; $P=.009$; high heterogeneity $\left.\left[I^{2}=66 \%\right]\right) .{ }^{4-6}$
Absolute risk reduction for a population with 2.5\% incidence of peanut allergy was 18 cases (95\% CI, 6-22 cases) per 1000 population. One trial (640 participants) reported significantly reduced allergic sensitization to peanut with early peanut introduction, but numerical data were not reported; a second trial (1168 participants) found no significant association (Figure 1B). ${ }^{4,6}$

For several key findings, there was moderate to high statistical heterogeneity. For the egg introduction and egg allergy analysis, heterogeneity was due to the abstract publication by Natsume and colleagues ${ }^{17}$-the authors declined to share further information about their study. The study by Perkin and colleagues, ${ }^{6}$ which used multiple allergenic food introduction, had findings that were consistent with other studies $^{15,16,18}$ in which egg was the only allergenic food used. For the egg introduction and egg sensitization analysis, heterogeneity was due to the abstract publication by Bellach and colleagues, ${ }^{16}$ which used specific IgE rather than skin prick testing to determine egg sensitization. For the peanut introduction and peanut allergy analysis, the high heterogeneity was attributed to the high treatment adherence in the study by Du Toit and colleagues ${ }^{4}$ compared with more variable treatment adherence in the study by Perkin and colleagues. ${ }^{6}$

In interventional studies, there was no association between timing of introduction of cow's milk ${ }^{19,20}$ (Figure 1) or other allergenic food and food allergy or allergic sensitization and no association between timing of introduction of one allergenic food and risk of food allergy or allergic sensitization to a different food (eTable 11 in the Supplement).

Abstract publications made a significant contribution to the analysis of egg introduction and egg allergy. However, the findings were similar in sensitivity analyses excluding abstract publications for which authors were unable to share full trial findings (eFigure 3A in the Supplement) or excluding studies at high or unclear risk of bias (eFigure 3B in the Supplement). In sensitivity analyses of allergic sensitization that excluded abstracts (eFigure 4A in the Supplement) or studies at high or unclear risk of bias (eFigure 4B in the Supplement), early egg introduction was associated with significantly reduced risk of allergic sensitization to egg.

Eighteen observational studies reported food allergy in 40194 participants, and 20 studies reported allergic sensitization in 23466 participants. One prospective cohort study (699 participants) found an association between early egg introduction and decreased egg allergy (odds ratio [OR], 0.29; 95\% CI, 0.15-0.56) and adjusted for possible reverse causation. ${ }^{21}$ Three cohort studies (13 472 participants), which could not be meta-analyzed because of statistical heterogeneity and heterogeneity of analysis methods (Figure 2A), found that early fish introduction (before age 6-9 months) was associated with reduced allergic sensitization to any allergen or food allergens. ${ }^{22-24}$ There was no association between timing of introduction of other allergenic foods and risk of food allergy or allergic sensitization. Assessment for publication bias in analyses of food allergy and allergic sensitization was not possible because of the limited number of studies in each meta-analysis. 


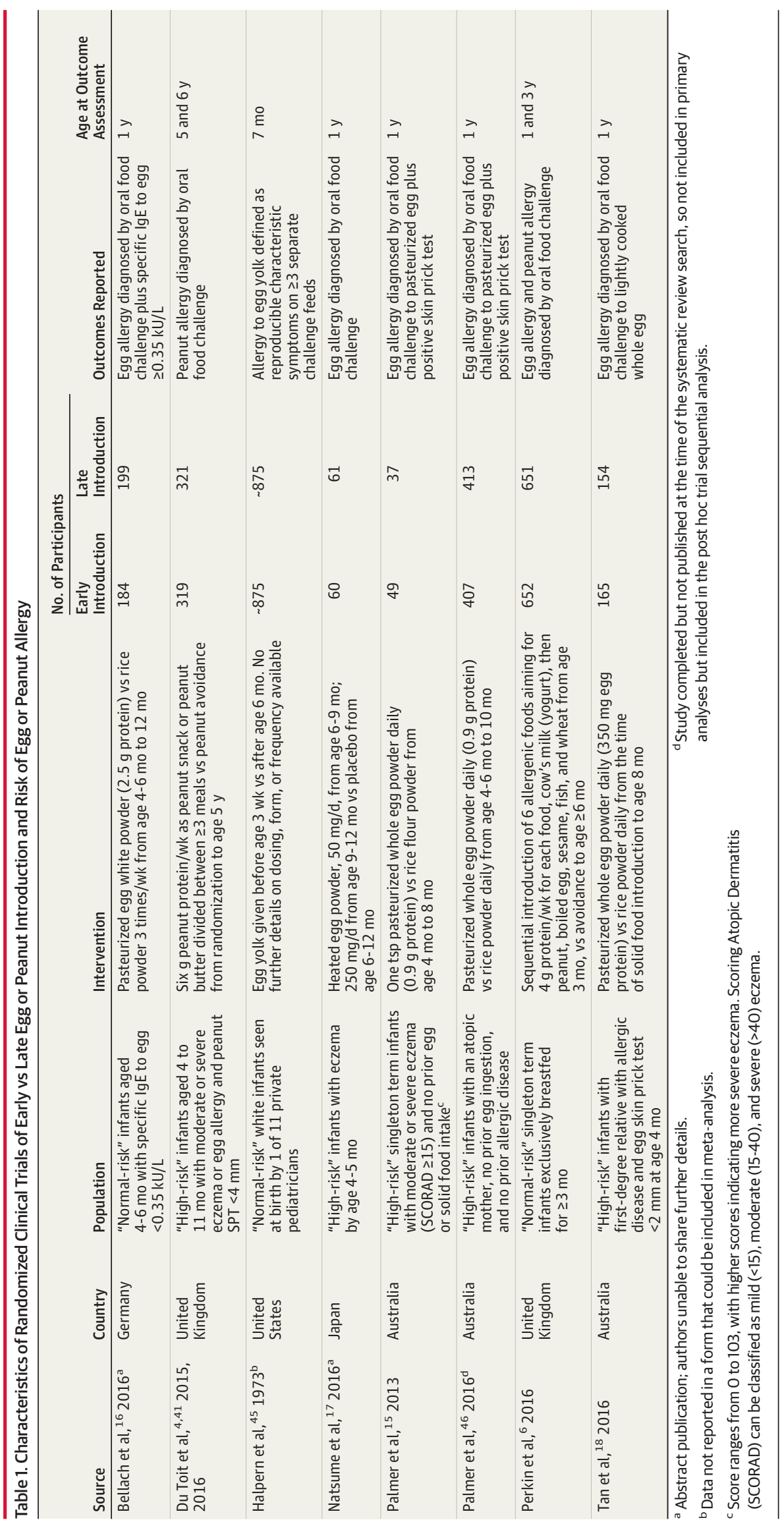




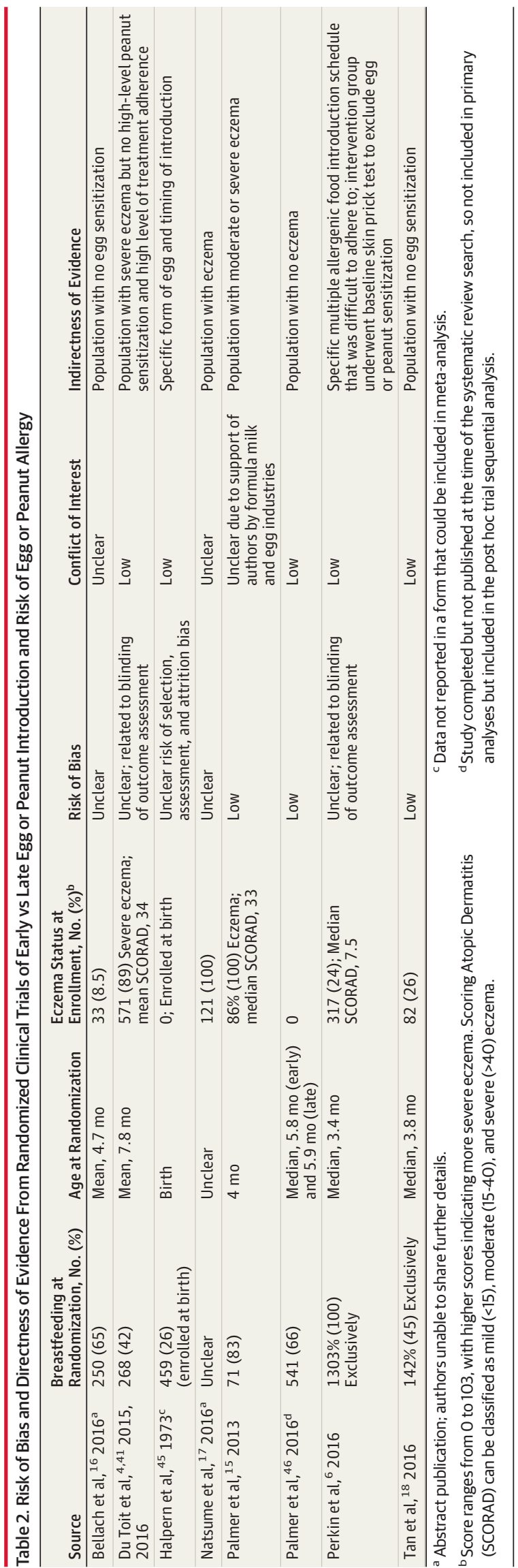

Risk of Allergic Rhinitis

Thirteen intervention trials (6333 participants) and 12 observational studies (25147 participants) reported allergic rhinitis. A summary of findings is shown in eTable 11 in the Supplement. Four cohort studies (12 781 participants) (Figure 2B) found fish introduction before age 6 to 12 months was associated with reduced allergic rhinitis at age 4 years or younger (OR, 0.59; 95\% CI, 0.40-0.87; high heterogeneity [ $\left.I^{2}=59 \%\right]$ ) or at age 5 to 14 years (OR, 0.68; 95\% CI, 0.47-0.98)..$^{22,23,25,26}$ In a sensitivity analysis excluding studies at high or unclear risk of bias (eFigure 5 in the Supplement), the association between early fish introduction and reduced allergic rhinitis at age 4 years or younger was not statistically significant. It was not possible to explain the heterogeneity in the fish introduction and allergic rhinitis analysis. In other intervention and observational studies, timing of allergenic food introduction was not associated with risk of allergic rhinitis. Assessment for publication bias in analyses of allergic rhinitis was not possible because of the limited number of studies in each meta-analysis.

\section{Risk of Wheeze}

Sixteen intervention trials (8433 participants) and 30 observational studies (65 601 participants) reported wheeze. A summary of findings is shown in eTable 11 in the Supplement. Three cohort studies (11155 participants) found that fish introduction before age 8 to 12 months was associated with reduced recurrent wheeze at age 4 years or younger (OR, 0.72 ; $95 \% \mathrm{CI}$, 0.59-0.87; no heterogeneity $\left.\left[I^{2}=0 \%\right]\right) .{ }^{23,25,27}$ However, 5 other studies (13033 participants) found no association between timing of fish introduction and wheeze. ${ }^{28-32}$ In other intervention and observational studies, there was no association between timing of allergenic food introduction and risk of wheeze. Assessment for publication bias in analyses of wheeze was not possible because of the limited number of studies in each meta-analysis.

\section{Risk of Eczema}

Seventeen intervention trials (6798 participants) and 37 observational studies (59120 participants) reported eczema. A summary of findings is shown in eTable 11 in the Supplement. For most analyses of intervention trials, data were sparse; for several analyses of observational studies, statistical heterogeneity was high. Overall, there was no consistent association between timing of allergenic food introduction and risk of eczema from either intervention or observational studies. Assessment for publication bias in analyses of eczema was not possible because of the limited number of studies.

\section{Risk of Autoimmune Diseases}

Five intervention trials (5623 participants) and 48 observational studies (63576 participants) reported autoimmune disease, and 2 other systematic reviews of observational data were identified. A summary of findings is shown in eTable 11 in the Supplement. The systematic reviews found no consistent evidence for an association between timing of gluten introduction and celiac disease. ${ }^{33,34}$ Intervention trials also found no association between timing of gluten introduction and celiac disease (Figure 3) or type 1 diabetes mellitus or 


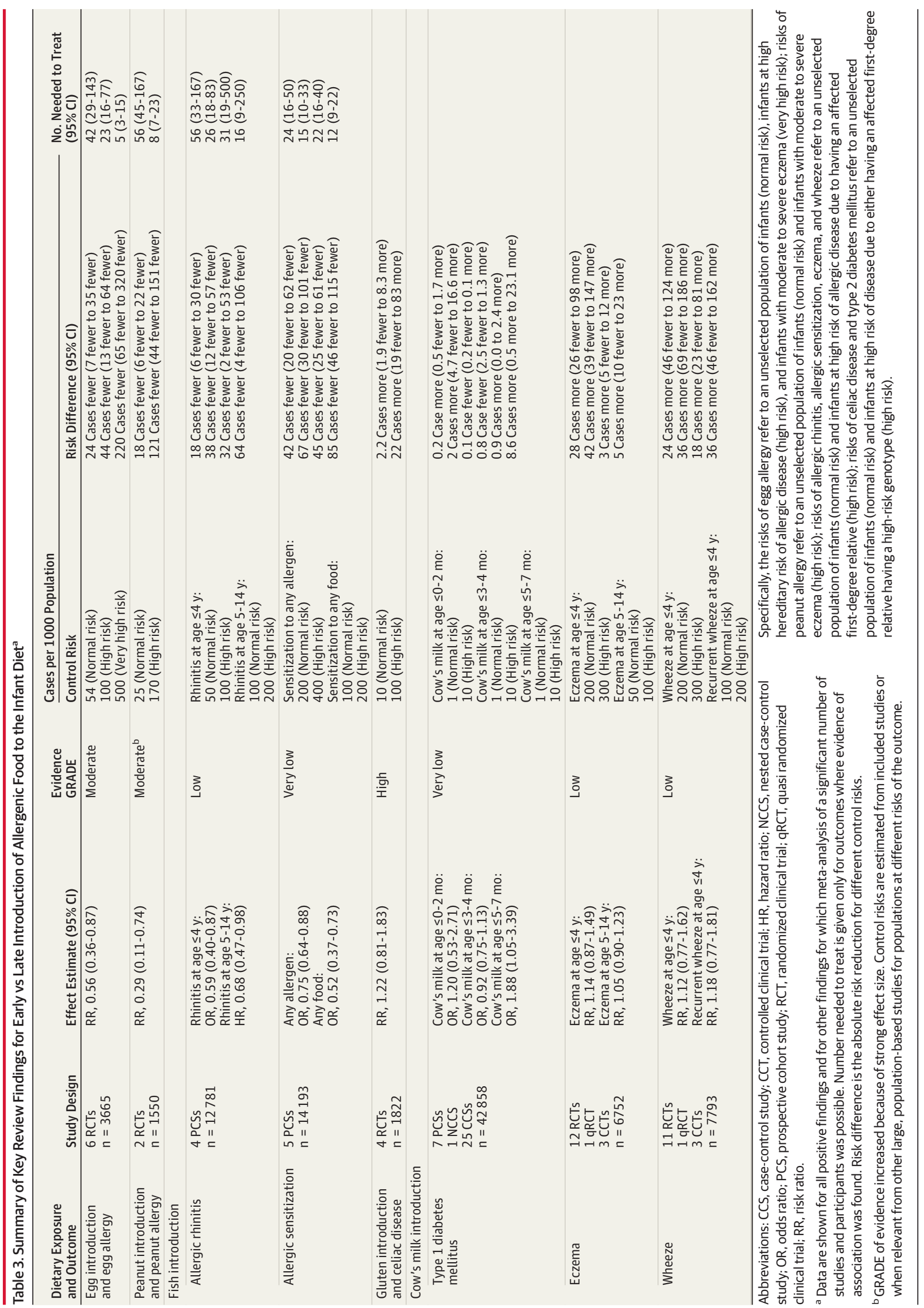




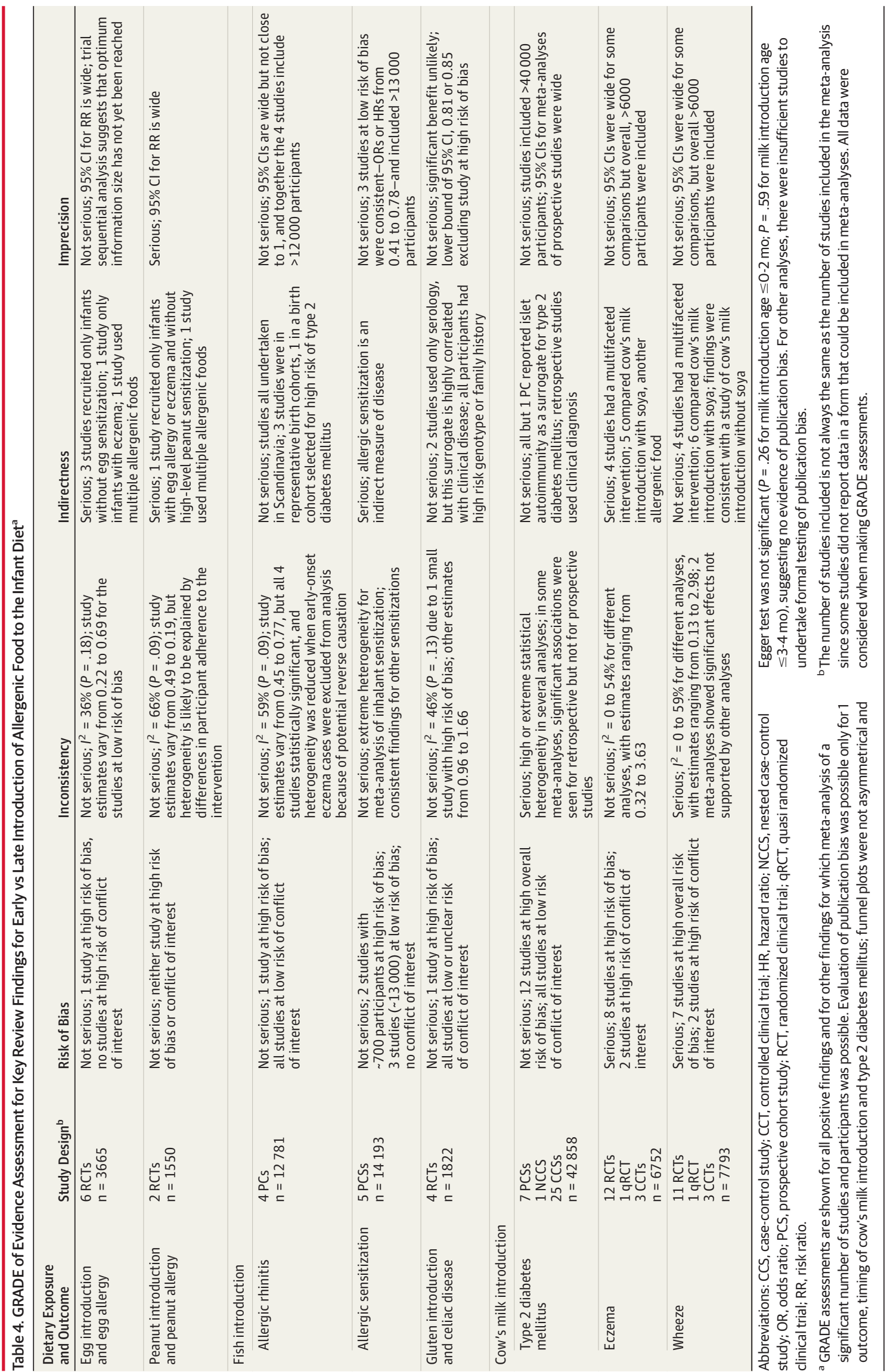


A Risk of food allergy

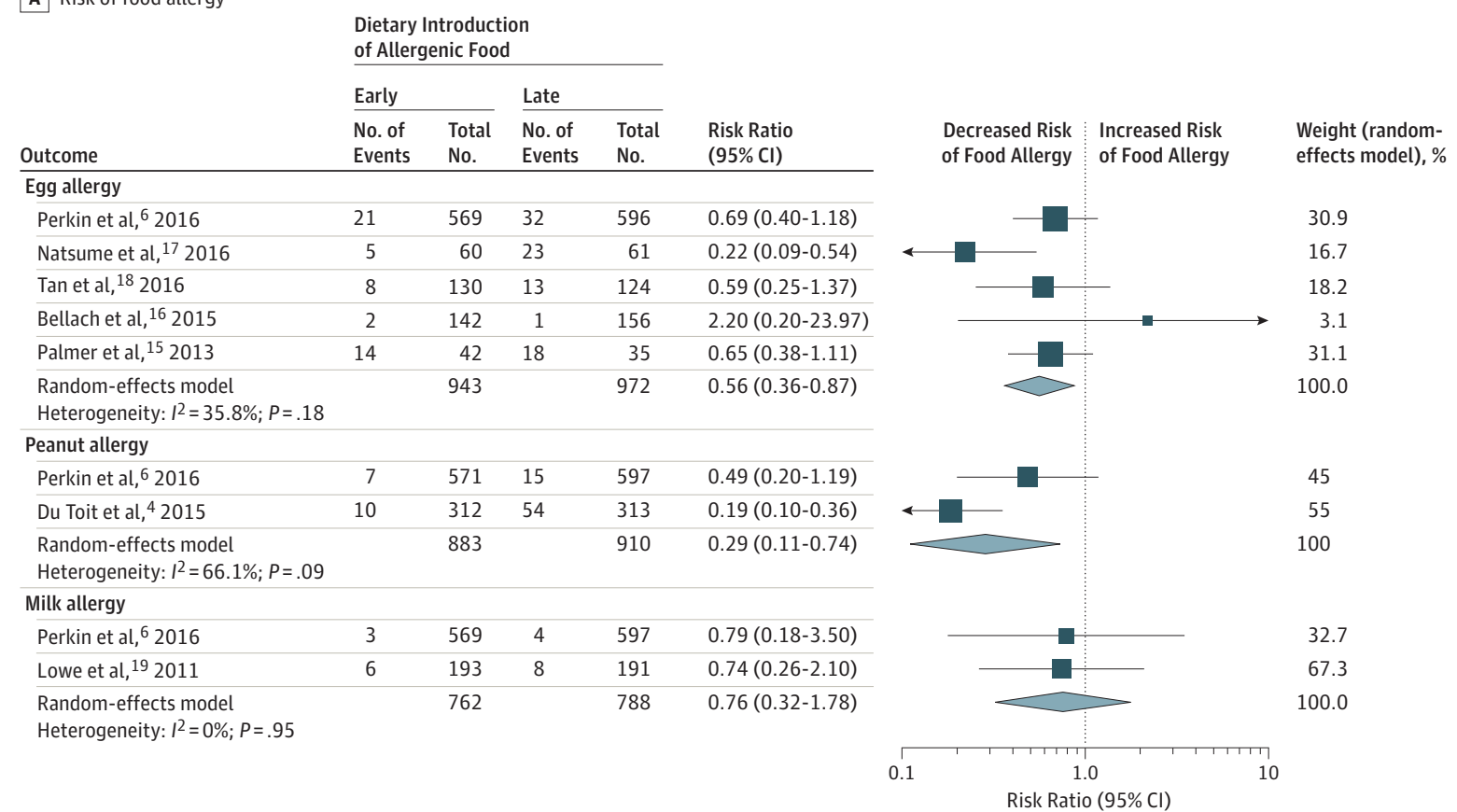

B Risk of allergic sensitization

\begin{tabular}{|c|c|c|c|c|c|}
\hline \multirow[b]{3}{*}{ Outcome } & \multicolumn{4}{|c|}{$\begin{array}{l}\text { Dietary Introduction } \\
\text { of Allergenic Food }\end{array}$} & \multirow[b]{3}{*}{$\begin{array}{l}\text { Risk Ratio } \\
(95 \% \mathrm{Cl})\end{array}$} \\
\hline & \multicolumn{2}{|l|}{ Early } & \multicolumn{2}{|l|}{ Late } & \\
\hline & $\begin{array}{l}\text { No. of } \\
\text { Events }\end{array}$ & $\begin{array}{l}\text { Total } \\
\text { No. }\end{array}$ & $\begin{array}{l}\text { No. of } \\
\text { Events }\end{array}$ & $\begin{array}{l}\text { Total } \\
\text { No. }\end{array}$ & \\
\hline \multicolumn{6}{|l|}{ Egg sensitization } \\
\hline Perkin et al, ${ }^{6} 2016$ & 29 & 568 & 37 & 599 & $0.83(0.52-1.33)$ \\
\hline Tan et al, 182016 & 13 & 122 & 25 & 122 & $0.52(0.28-0.97)$ \\
\hline Bellach et al, ${ }^{16} 2015$ & 8 & 142 & 4 & 156 & $2.20(0.68-7.14)$ \\
\hline Palmer et al, 152013 & 19 & 42 & 22 & 35 & $0.72(0.47-1.09)$ \\
\hline $\begin{array}{l}\text { Random-effects model } \\
\text { Heterogeneity: } I^{2}=37 \% ; P=.19\end{array}$ & & 874 & & 912 & $0.77(0.53-1.11)$ \\
\hline \multicolumn{6}{|l|}{ Peanut sensitization } \\
\hline Perkin et al, ${ }^{6} 2016$ & 22 & 569 & 34 & 599 & $0.68(0.40-1.15)$ \\
\hline \multicolumn{6}{|l|}{ Milk sensitization } \\
\hline Perkin et al, ${ }^{6} 2016$ & 6 & 568 & 11 & 599 & $0.58(0.21-1.55)$ \\
\hline Lowe et al, ${ }^{19} 2011$ & 9 & 178 & 12 & 178 & $0.75(0.32-1.74)$ \\
\hline Kjellman and Johansson, ${ }^{20} 1979$ & 4 & 25 & 4 & 23 & $0.92(0.26-3.26)$ \\
\hline $\begin{array}{l}\text { Random-effects model } \\
\text { Heterogeneity: } I^{2}=0 \% ; P=.84\end{array}$ & & 771 & & 800 & $0.72(0.40-1.27)$ \\
\hline
\end{tabular}

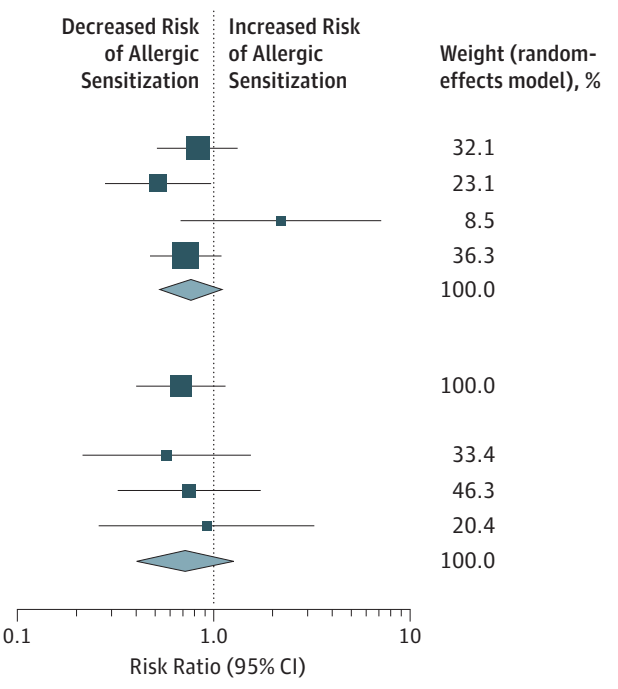

Effect of early vs late dietary introduction of allergenic food (egg, milk, or peanut) on risk of food allergy (A) or allergic sensitization (B) to the same food. allergic sensitization (B) to the same food. The size of the data markers is Data are from randomized clinical trials. "Event" refers to food allergy (A) or proportional to study weights in the meta-analysis.

milk introduction and type 1 diabetes mellitus. ${ }^{7,35-38}$ In sensitivity analyses excluding studies at high or unclear risk of bias (eFigure 6A in the Supplement) or only high risk of bias (eFigure 6B in the Supplement), there was no association between timing of gluten introduction and celiac disease. For the gluten introduction and celiac disease analysis, heterogeneity was due to the study by Sellitto and colleagues ${ }^{37}$-in this study, the control group had not yet ingested gluten at the time of outcome assessment so celiac disease or serology could not manifest.

Observational studies found no association between timing of gluten introduction and risk of celiac disease or inflammatory bowel disease; milk introduction and celiac disease or juvenile idiopathic arthritis; or timing of allergenic food 
A Risk of allergic sensitization

\begin{tabular}{|c|c|c|c|c|c|}
\hline Allergen & $\begin{array}{l}\text { No. of } \\
\text { Events }\end{array}$ & $\begin{array}{l}\text { Total } \\
\text { No. }\end{array}$ & $\begin{array}{l}\text { Odds Ratio } \\
(95 \% \mathrm{Cl})\end{array}$ & $\begin{array}{r}\text { Decreased Risk } \\
\text { of Allergic } \\
\text { Sensitization }\end{array}$ & $\begin{array}{l}\text { Increased RISk } \\
\text { of Allergic } \\
\text { Sensitization }\end{array}$ \\
\hline \multicolumn{6}{|l|}{ Any allergen } \\
\hline Nwaru et al, 262013 & 1379 & 3675 & $0.71(0.55-0.92)$ & - & \\
\hline Kull et al, ${ }^{23} 2006$ & 612 & 2545 & $0.78(0.64-0.95)$ & $\rightarrow$ & \\
\hline \multicolumn{6}{|l|}{ Any aeroallergen } \\
\hline Alm et al, 222011 & 153 & 3481 & $0.50(0.33-0.76)$ & - & \\
\hline Nwaru et al, ${ }^{24} 2010$ & 947 & 3675 & $0.66(0.44-1.00)$ & $\longrightarrow$ & \\
\hline Zutavern et al, ${ }^{30} 2004$ & 92 & 552 & $1.19(0.74-1.89)$ & & $=$ \\
\hline \multicolumn{6}{|l|}{ Any food } \\
\hline Alm et al, 222011 & 298 & 3636 & $0.59(0.42-0.82)$ & - & \\
\hline Nwaru et al, ${ }^{24} 2010$ & 881 & 3675 & $0.41(0.25-0.67)$ & - & \\
\hline \multicolumn{6}{|l|}{ Cow's milk } \\
\hline Nwaru et al, 262013 & 515 & 3675 & $0.63(0.44-0.90)$ & - & \\
\hline \multicolumn{6}{|l|}{ Egg } \\
\hline Nwaru et al, 262013 & 368 & 3675 & $0.64(0.42-0.97)$ & $\longrightarrow$ & \\
\hline & & & & Odds Ratic & $\begin{array}{l}0 \\
0 \\
(95 \% \mathrm{Cl})\end{array}$ \\
\hline
\end{tabular}

B Risk of allergic rhinitis

\begin{tabular}{|c|c|c|c|c|c|c|}
\hline Source & $\begin{array}{l}\text { No. of } \\
\text { Events }\end{array}$ & $\begin{array}{l}\text { Total } \\
\text { No. }\end{array}$ & $\begin{array}{l}\text { Odds Ratio } \\
(95 \% \mathrm{Cl})\end{array}$ & $\begin{array}{r}\text { Decreased Risk } \\
\text { of Allergic } \\
\text { Rhinitis }\end{array}$ & $\begin{array}{l}\text { Increased Risk } \\
\text { of Allergic } \\
\text { Rhinitis }\end{array}$ & $\begin{array}{l}\text { Weight (random- } \\
\text { effects model), \% }\end{array}$ \\
\hline \multicolumn{7}{|c|}{ Age at outcome $=$ birth to $4 \mathrm{y}$} \\
\hline Alm et al, 222011 & 246 & 4465 & $0.49(0.27-0.89)$ & & & 24.0 \\
\hline Kull et al, ${ }^{23} 2006$ & 373 & 3575 & $0.77(0.61-0.97)$ & & & 46.8 \\
\hline Nafstad et al, ${ }^{25} 2003$ & 98 & 2271 & $0.45(0.27-0.74)$ & - & & 29.1 \\
\hline $\begin{array}{l}\text { Random-effects model } \\
\text { Heterogeneity: } I^{2}=59 .\end{array}$ & $P=.09$ & & $0.59(0.40-0.87)$ & & & 100 \\
\hline \multicolumn{7}{|l|}{ Age at outcome $=5$ to $14 \mathrm{y}$} \\
\hline \multirow[t]{2}{*}{ Nwaru et al, ${ }^{26} 2013$} & 442 & 3112 & $0.68(0.47-0.98)$ & & & 100 \\
\hline & & & & & $\begin{array}{l}0 \\
0(95 \% \mathrm{Cl})\end{array}$ & \\
\hline
\end{tabular}

Association between early dietary introduction of fish and different forms of allergic sensitization (A) or allergic rhinitis (B). Data are from observational studies. The size of the data markers in panel $B$ is proportional to study weights in the allergic rhinitis meta-analysis. Age represents age at outcome assessment.

Figure 3. Early Gluten Introduction and Risk of Celiac Disease

\begin{tabular}{|c|c|c|c|c|c|c|c|c|}
\hline \multirow[b]{3}{*}{ Outcome } & \multicolumn{4}{|c|}{ Dietary Introduction of Gluten } & \multirow[b]{3}{*}{$\begin{array}{l}\text { Risk Ratio } \\
(95 \% \mathrm{Cl})\end{array}$} & \multirow[b]{3}{*}{$\begin{array}{l}\text { Decreased Risk } \\
\text { of Celiac Disease }\end{array}$} & \multirow[b]{3}{*}{$\begin{array}{l}\text { Increased Risk } \\
\text { of Celiac Disease }\end{array}$} & \multirow[b]{3}{*}{$\begin{array}{l}\text { Weight (random- } \\
\text { effects model), \% }\end{array}$} \\
\hline & \multicolumn{2}{|l|}{ Early } & \multicolumn{2}{|l|}{ Late } & & & & \\
\hline & $\begin{array}{l}\text { No. of } \\
\text { Events }\end{array}$ & $\begin{array}{l}\text { Total } \\
\text { No. }\end{array}$ & $\begin{array}{l}\text { No. of } \\
\text { Events }\end{array}$ & $\begin{array}{l}\text { Total } \\
\text { No. }\end{array}$ & & & & \\
\hline Beyerlein et al,35 2014 & 14 & 77 & 8 & 73 & $1.66(0.74-3.72)$ & & 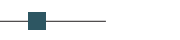 & 18.0 \\
\hline Lionetti et al, ${ }^{36} 2014$ & 53 & 328 & 64 & 379 & $0.96(0.69-1.33)$ & & - & 43.1 \\
\hline Vriezinga et al,7 2014 & 44 & 475 & 36 & 465 & $1.20(0.78-1.82)$ & & - & 36.8 \\
\hline Sellitto et al, ${ }^{37} 2012$ & 8 & 13 & 0 & 12 & $15.74(1.01-245.35)$ & & 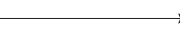 & 2.1 \\
\hline \multirow{2}{*}{$\begin{array}{l}\text { Random-effects model } \\
\text { Heterogeneity: } I^{2}=46.1 \% ; P=.13\end{array}$} & & 893 & & 929 & $1.22(0.81-1.83)$ & & & 100.0 \\
\hline & & & & & & $\begin{array}{r}1 \\
\text { Risk Rati }\end{array}$ & $(95 \% \mathrm{Cl})$ & \\
\hline
\end{tabular}

Effect of early vs late dietary introduction of gluten on risk of celiac disease. Data are from randomized clinical trials. "Event" refers to celiac disease. The size of the data markers is proportional to study weights in the meta-analysis.

introduction and risk of type 1 diabetes mellitus. There was no evidence of publication bias in analyses of milk introduction and type 1 diabetes mellitus $(P=.26$ and $P=.59$ by Egger test), and assessment for publication bias was not possible for other comparisons because of the limited number of studies in each meta-analysis.

\section{GRADE Evaluation of Certainty of Findings}

Key findings were affected by the study of select populations with either active allergic disease, absence of allergic sensitization to the intervention food, or both. There was also significant variation between the populations studied in each trial. Interventions varied from early short-term 
(3-4 days) introduction of an allergenic food to early sustained introduction of single or multiple allergenic foods to trials of delayed allergenic food introduction and multifaceted studies that also included other dietary components, often together with environmental control measures such as tobacco smoke and house dust mite avoidance. GRADE of evidence was therefore reduced in several analyses because of indirectness of the population or intervention (Table 4). GRADE of evidence for the egg and peanut findings was also reduced because of imprecise effect estimates but was increased for peanut because of the strong effect size seen in the trial of Du Toit and colleagues. ${ }^{4}$

\section{Trial Sequential Analysis of Moderate- or High-Certainty Findings}

Peanut introduction and peanut allergy were not evaluated using trial sequential analysis because of insufficient data in the meta-analysis to estimate a sufficient number of points for the monitoring boundaries. There were also insufficient data to perform trial sequential analysis for $10 \%$ or $20 \%$ relative risk reduction for other findings. Whether early egg introduction was associated with a $30 \%$ reduction in risk of egg allergy using trial sequential analysis was assessed. The heterogeneityadjusted and unadjusted optimal information sizes for detection of a 30\% relative risk reduction for egg allergy were 8643 and 5239 study participants, respectively. Trial sequential analysis for this outcome is shown in eFigures 7A and 7B in the Supplement. Although the conventional line of statistical significance was crossed $(z=1.96)$ in both analyses, the optimal information size was not reached in either case. The cumulative $z$ score did not cross the monitoring boundary, although it is close in unadjusted trial sequential analysis. It cannot be confidently concluded that early egg introduction reduces egg allergy by at least $30 \%$; further trials are required to quantify the treatment effect.

Trial sequential analysis was also used to evaluate whether early gluten introduction increases celiac disease risk by $30 \%$. The heterogeneity-adjusted and unadjusted optimal information sizes for detection of a $30 \%$ increase in relative risk of celiac disease were 3599 and 9497 study participants, respectively. Trial sequential analysis for this outcome is shown in eFigures 7C and 7D in the Supplement. The conventional line of statistical significance was not crossed and the optimal information size was not reached. The cumulative $\mathrm{z}$ score was close to the line of futility in unadjusted trial sequential analysis. It cannot be confidently concluded that further studies of timing of gluten introduction and risk of celiac disease are futile.

\section{Discussion}

This systematic review found evidence that timing of introduction of certain allergenic foods to the infant diet was associated with risk of allergic disease but not risk of autoimmune disease. There was moderate-certainty evidence that introduction of egg to the infant diet at age 4 to 6 months was associated with reduced egg allergy and introduction of peanut at age 4 to 11 months was associated with reduced peanut allergy compared with later introduction of these foods. There was lowcertainty evidence that fish introduction before age 6 to 12 months was associated with reduced allergic rhinitis and very low-certainty evidence that fish introduction before age 6 to 9 months was associated with reduced allergic sensitization.

The evidence base for a relationship between early allergenic food introduction and food allergy to the same food was limited to a relatively small number of studies and events and was only statistically significant for egg and peanut. Heterogeneity-adjusted trial sequential analysis of early egg introduction for egg allergy suggests that further trials are warranted to confirm the findings and quantify the magnitude of the treatment effect. Heterogeneity for egg introduction was attributable to 1 small study presented in abstract form only. ${ }^{13}$ Trial sequential analysis without adjustment for heterogeneity showed stronger evidence that early egg introduction reduced risk of egg allergy by $30 \%$ or more but without crossing the trial sequential monitoring boundary. Trial sequential analysis of early peanut introduction for peanut allergy was not possible due to the small number of studies and events in this analysis. The inability to undertake trial sequential analysis for this outcome emphasizes the value of further intervention studies of peanut introduction and peanut allergy. ${ }^{39}$

These findings are consistent with a large body of experimental data in various animal models in which early enteral antigen exposure is established as effective for preventing allergic sensitization to the same antigen. ${ }^{40}$ This phenomenon of oral tolerance has not been directly shown to occur in humans until recently. ${ }^{4,41}$ Oral tolerance in humans appears to be antigen specific, with no data showing early introduction of one allergenic food influences the development of allergy to a different allergenic food.

In contrast to egg and peanut allergy, this review found that oral tolerance was not relevant to celiac disease, suggesting that the findings may not be generalizable beyond food allergy mediated by IgE antibodies. Trial sequential analysis of gluten introduction and celiac disease risk found that further trials would not be futile; however, available data show no evidence of an association. Ongoing work is evaluating a potential role for oral tolerance in other autoimmune diseases; for example, the induction of immune tolerance to insulin for preventing type 1 diabetes mellitus. ${ }^{42}$ There was also no consistent evidence that early cow's milk introduction influences risk of type 1 diabetes mellitus, which is consistent with recent literature; for example, a trial of extensively hydrolyzed vs intact infant formula showed no effect on type 1 diabetes mellitus risk. ${ }^{43}$

There was lower-certainty evidence that early fish introduction was associated with reduced allergic sensitization or rhinitis. Sensitivity analysis of studies at low risk of bias found that the association with allergic rhinitis at age 4 years or younger was not statistically significant. One plausible biological mechanism is that early exposure to the antiinflammatory effects of omega-3 polyunsaturated fatty acids present in fish might influence development or expression of allergic sensitization and associated inflammatory disease. ${ }^{44}$ 
These data conflict with previous recommendations to delay introduction of allergenic foods to the infant diet and suggest that current guidelines that do not advise early introduction of allergenic foods may need to be revised. ${ }^{1-3}$ They are, however, consistent with 1 recent intervention trial and a consensus statement regarding introduction of peanut to the infant diet, ${ }^{4,5}$ and any differences in conclusions from other trials can be explained by the increased statistical power derived from meta-analysis.

Despite the comprehensive approach used in this review, it was not possible to exclude clinically important effects in most analyses because there were few studies. Certainty of evidence was downgraded because of imprecision and indirectness and variation in interventions used and populations studied. However, there was not a clear difference in outcome among studies of different populations in our analyses; for example, in meta-analysis of egg introduction and egg allergy, 3 studies undertaken in normal-risk, high-risk, and very high- risk populations had similar findings. Risk-of-bias assessment used different instruments for intervention and observational studies, which may not be directly comparable.

These systematic review findings should not automatically lead to new recommendations to feed egg and peanut to all infants. The imprecise effect estimates, issues regarding indirectness, and inconclusive trial sequential analysis findings all need to be considered, together with a careful assessment of the safety and acceptability of early egg and peanut introduction in different populations.

\section{Conclusions}

In this systematic review, early introduction of egg or peanut to the infant diet was associated with lower risk of developing egg or peanut allergy. These findings must be considered in the context of limitations in the primary studies.

\section{ARTICLE INFORMATION}

Author Contributions: Dr Boyle had full access to all of the data in the study and takes responsibility for the integrity of the data and the accuracy of the data analysis. Drs lerodiakonou and Garcia-Larsen contributed equally to the manuscript.

Concept and design: Garcia-Larsen, Geoghegan, Leonardi-Bee, Boyle.

Acquisition, analysis, or interpretation of data: All authors.

Drafting of the manuscript: lerodiakonou, Garcia-Larsen, Groome, Chivinge, Geoghegan, Reeves, Tagiyeva, Boyle.

Critical revision of the manuscript for important intellectual content: lerodiakonou, Garcia-Larsen, Logan, Cunha, Robinson, Geoghegan, Jarrold, Nurmatov, Trivella, Leonardi-Bee, Boyle. Statistical analysis: Ierodiakonou, Garcia-Larsen, Chivinge, Geoghegan, Jarrold, Trivella, Leonardi-Bee.

Administrative, technical, or material support: Garcia-Larsen, Cunha, Chivinge, Geoghegan, Reeves, Nurmatov, Boyle.

Study supervision: Garcia-Larsen, Nurmatov, Boyle.

Conflict of Interest Disclosures: All authors have completed and submitted the ICMJE Form for Disclosure of Potential Conflicts of Interest. Drs lerodiakonou, Garcia-Larsen, Cunha, Tagiyeva-Milne, Nurmatov, Leonardi-Bee, and Boyle reported receiving support from the UK Food Standards Agency for the submitted work. Dr Boyle reported receipt of consultancy fees from Imperial Consultants for the work. No other disclosures were reported.

Funding/Support: This work was funded by the Food Standards Agency and supported by the National Institute for Health Research Biomedical Research Centre and the MRC-Asthma UK Centre in Allergic Mechanisms of Asthma. Dr Trivella was supported by Cancer Research UK.

Role of the Funder/Sponsor: The Food Standards Agency commissioned this work, commissioned external peer review of the study protocol, statistical methods, and study report, and thereby contributed to the design and conduct of the study and interpretation of data. The Food Standards Agency contributed to review and approval of the manuscript. The Food Standards Agency had no role in the collection, management, or analysis of data; preparation of the manuscript; or decision to submit the manuscript for publication. The National Institute for Health Research and Cancer Research UK had no role in the design and conduct of the study; collection, management, analysis, and interpretation of data; preparation, review, or approval of the manuscript; or decision to submit the manuscript for publication.

Previous Presentation: A small part of the information reported in this article has been presented as a poster at the Medela 10th International Breastfeeding and Lactation Symposium, Warsaw, Poland, April 2015.

Additional Contributions: Independent peer review of study protocol and report: Graham Devereux, PhD, University of Aberdeen (compensation received) and Carina Venter, PhD, Cincinnati Children's Hospital (compensation received); members of the UK Food Standards Agency, the Committee on Toxicity of Chemicals in Food, Consumer Products and the Environment, and the UK Scientific Advisory Committee on Nutrition (no compensation received). Advice on statistical analysis: Peter Burney, PhD, Imperial College London (no compensation received), Doug Altman, PhD, Oxford University (no compensation received). Translation of foreign language reports: Yujie Zhao, PhD, Szymon Mikolajewski, BSc, Andre Amaral, PhD, Mari Kihara, PhD, Christian Nielsen, PhD, Radoslav Latinovic, BSc, Stephanie MacNeill, PhD, Andreas Forsters, PhD, Daniel Munblit, MD, Sze-Chin Tan, MD, and Claudia Gore, MD, all from Imperial College London (no compensation received). Literature search training: Jackie Cousins, BSc, Imperial College London (no compensation received). Collation of data for risk of bias analysis and characteristics of included studies tables in the full Food Standards Agency report: Evangelia Andreou, PhD, Cambridge University (compensation received). Production of graphics for statistical figures: Jamie Reeves, BSc, Imperial College London (no compensation received). Comments on a previous version of the manuscript: Michael Perkin, PhD, St George's University London (no compensation received).

\section{REFERENCES}

1. Muraro A, Halken S, Arshad SH, et al; EAACI Food Allergy and Anaphylaxis Guidelines Group. EAACl food allergy and anaphylaxis guidelines: primary prevention of food allergy. Allergy. 2014;69(5): 590-601.

2. Fleischer DM, Spergel JM, Assa'ad AH, Pongracic JA. Primary prevention of allergic disease through nutritional interventions. J Allergy Clin Immunol Pract. 2013;1(1):29-36.

3. Chan ES, Cummings $C$, Atkinson A, et al. Dietary exposures and allergy prevention in high-risk infants: a joint position statement of the Canadian Society of Allergy and Clinical Immunology and the Canadian Paediatric Society. Allergy Asthma Clin Immunol. 2014;10(1):45.

4. Du Toit G, Roberts G, Sayre PH, et al; LEAP Study Team. Randomized trial of peanut consumption in infants at risk for peanut allergy. N Engl J Med. 2015; 372(9):803-813.

5. Fleischer DM, Sicherer S, Greenhawt M, et al; American Academy of Allergy, Asthma and Immunology; American Academy of Pediatrics, American College of Allergy; Asthma and Immunology, Australasian Society of Clinical Immunology and Allergy; Canadian Society of Allergy and Clinical Immunology; European Academy of Allergy and Clinical Immunology; Israel Association of Allergy and Clinical Immunology; Japanese Society for Allergology; Society for Pediatric Dermatology; World Allergy Organization. Consensus communication on early peanut introduction and the prevention of peanut allergy in high-risk infants. J Allergy Clin Immunol. 2015;136 (2):258-261.

6. Perkin MR, Logan K, Tseng A, et al; EAT Study Team. Randomized trial of introduction of allergenic foods in breast-fed infants. N Engl J Med. 2016;374 (18):1733-1743

7. Vriezinga SL, Auricchio R, Bravi E, et al. Randomized feeding intervention in infants at high risk for celiac disease. N Engl J Med. 2014;371(14): 1304-1315.

8. Boyle RJ, lerodiakonou D, Khan T, et al. Hydrolysed formula and risk of allergic or 
autoimmune disease: systematic review and meta-analysis. BMJ. 2016;352:1974.

9. Herold KC, Vignali DA, Cooke A, Bluestone JA. Type 1 diabetes: translating mechanistic observations into effective clinical outcomes. Nat Rev Immunol. 2013;13(4):243-256.

10. Johansson SG, Bieber T, Dahl R, et al. Revised nomenclature for allergy for global use: report of the Nomenclature Review Committee of the World Allergy Organization, October 2003. J Allergy Clin Immunol. 2004;113(5):832-836.

11. Moher D, Liberati A, Tetzlaff J, Altman DG; PRISMA Group. Preferred reporting items for systematic reviews and meta-analyses: the PRISMA statement. BMJ. 2009;339:b2535.

12. Food Allergen Labeling and Consumer Protection Act. II. Vol Public Law 108-2822004.

13. Kung J, Chiappelli F, Cajulis OO, et al. From systematic reviews to clinical recommendations for evidence-based health care: validation of Revised Assessment of Multiple Systematic Reviews (R-AMSTAR) for grading of clinical relevance. Open Dent J. 2010;4:84-91.

14. Boyle RJ, Garcia-Larsen V, Reeves $T$, Leonardi-Bee J. Review of scientific published literature on infant feeding and development of atopic and autoimmune disease, B: timing of allergenic food introduction. International Prospective Register of Systematic Reviews (PROSPERO). 2013. http://www.crd.york .ac.uk/PROSPERO/display_record.asp?ID =CRD42013004239. Accessed July 14, 2016.

15. Palmer DJ, Metcalfe J, Makrides M, et al. Early regular egg exposure in infants with eczema: a randomized controlled trial. J Allergy Clin Immunol 2013;132(2):387-92.

16. Bellach J, Schwartz V, Ahrens B, et al. Early introduction of hen's egg during weaning results in frequent allergic reactions: first results from a randomized placebo-controlled trial on hen's egg allergy prevention. Allergy. 2015;70(suppl 101):111.

17. Natsume O, Kabashima S, Nakasato J, et al. Early introduction of egg for infants with atopic dermatitis to prevent egg allergy: a double-blind placebo-controlled randomized clinical trial. J Allergy Clin Immunol. 2016;137(2)(suppl 1):AB98.

18. Tan JWL, Valerio C, Barnes EH, Van Asperen PP, Kakakios AM, Campbell DE. Early introduction of dietary egg reduces egg sensitization at 12 months of age in infants at risk of allergic disease. J Allergy Clin Immunol. 2016;137(2)(suppl 1):AB398.

19. Lowe AJ, Hosking CS, Bennett CM, et al. Effect of a partially hydrolyzed whey infant formula at weaning on risk of allergic disease in high-risk children: a randomized controlled trial. J Allergy Clin Immunol. 2011;128(2):360-365.

20. Kjellman NI, Johansson SG. Soy versus cow's milk in infants with a biparental history of atopic disease: development of atopic disease and immunoglobulins from birth to 4 years of age. Clin Allergy. 1979;9(4):347-358.

21. Koplin J, Osborne N, Martin P, et al. Does age of introduction of foods affect the risk of having egg allergy? a population-based study of an infant cohort. Allergy. 2010;65:312.

22. Alm B, Goksör E, Thengilsdottir H, et al. Early protective and risk factors for allergic rhinitis at age 41/2 yr. Pediatr Allergy Immunol. 2011;22(4):398-404. 23. Kull I, Bergström A, Lilja G, Pershagen G, Wickman M. Fish consumption during the first year of life and development of allergic diseases during childhood. Allergy. 2006;61(8):1009-1015.

24. Nwaru BI, Erkkola M, Ahonen S, et al. Age at the introduction of solid foods during the first year and allergic sensitization at age 5 years. Pediatrics. 2010;125(1):50-59.

25. Nafstad P, Nystad W, Magnus P, Jaakkola JJ. Asthma and allergic rhinitis at 4 years of age in relation to fish consumption in infancy. J Asthma. 2003:40(4):343-348.

26. Nwaru BI, Takkinen HM, Niemelä O, et al. Timing of infant feeding in relation to childhood asthma and allergic diseases. J Allergy Clin Immunol. 2013;131(1):78-86.

27. Goksor $\mathrm{E}$, Alm B, Thengilsdottir $\mathrm{H}$, et al. Neonatal antibiotic treatment is a risk factor for multiple trigger wheeze at age $41 / 2$ years. Pediatr Allergy Immunol. 2009;20:17.

28. Kiefte-de Jong JC, de Vries JH, Franco OH, et al. Fish consumption in infancy and asthma-like symptoms at preschool age. Pediatrics. 2012;130 (6):1060-1068.

29. Hesselmar B, Saalman R, Rudin A, Adlerberth I, Wold A. Early fish introduction is associated with less eczema, but not sensitization, in infants. Acta Paediatr. 2010;99(12):1861-1867.

30. Zutavern A, von Mutius E, Harris J, et al. The introduction of solids in relation to asthma and eczema. Arch Dis Child. 2004;89(4):303-308.

31. Virtanen SM, Kaila M, Pekkanen J, et al. Early introduction of oats associated with decreased risk of persistent asthma and early introduction of fish with decreased risk of allergic rhinitis. Br J Nutr. 2010;103(2):266-273

32. Nwaru BI, Craig LCA, Allan $\mathrm{K}$, et al. Breastfeeding and introduction of complementary foods during infancy in relation to the risk of asthma and atopic diseases up to 10 years. Clin Exp Allergy. 2013;43(11):1263-1273.

33. Szajewska $H$, Chmielewska A, Pieścik-Lech $M$, et al; PREVENTCD Study Group. Systematic review: early infant feeding and the prevention of coeliac disease. Aliment Pharmacol Ther. 2012;36(7):607 618.
34. Pinto-Sánchez MI, Verdu EF, Liu E, et al. Gluten introduction to infant feeding and risk of celiac disease: systematic review and meta-analysis. J Pediatr. 2016;168:132-43.e3.

35. Beyerlein A, Chmiel R, Hummel S, Winkler C, Bonifacio $\mathrm{E}$, Ziegler $\mathrm{AG}$. Timing of gluten introduction and islet autoimmunity in young children: updated results from the BABYDIET study. Diabetes Care. 2014;37(9):e194-e195.

36. Lionetti E, Castellaneta S, Francavilla R, et al; SIGENP (Italian Society of Pediatric Gastroenterology, Hepatology, and Nutrition) Working Group on Weaning and CD Risk. Introduction of gluten, HLA status, and the risk of celiac disease in children. N Engl J Med. 2014;371 (14):1295-1303.

37. Sellitto M, Bai G, Serena G, et al. Proof of concept of microbiome-metabolome analysis and delayed gluten exposure on celiac disease autoimmunity in genetically at-risk infants. PLoS One. 2012;7(3):e33387

38. Savilahti E, Saarinen KM. Early infant feeding and type 1 diabetes. Eur J Nutr. 2009;48(4):243-249.

39. Preventing atopic dermatitis and allergies in children. https://clinicaltrials.gov/ct2/show /NCT02449850. Accessed July 14, 2016

40. Wells HG. Studies on the chemistry of anaphylaxis. J Infect Dis. 1911;8:147-171.

41. Du Toit G, Sayre PH, Roberts G, et al; Immune Tolerance Network LEAP-On Study Team. Effect of avoidance on peanut allergy after early peanut consumption. N Engl J Med. 2016;374(15):1435-1443.

42. Bonifacio E, Ziegler AG, Klingensmith G, et al; Pre-POINT Study Group. Effects of high-dose oral insulin on immune responses in children at high risk for type 1 diabetes: the Pre-POINT randomized clinical trial. JAMA. 2015;313(15):1541-1549.

43. Knip M, Åkerblom HK, Becker D, et al; TRIGR Study Group. Hydrolyzed infant formula and early $\beta$-cell autoimmunity: a randomized clinical trial. JAMA. 2014:311(22):2279-2287.

44. Miles EA, Calder PC. Omega- 6 and omega-3 polyunsaturated fatty acids and allergic diseases in infancy and childhood. Curr Pharm Des. 2014;20 (6):946-953

45. Halpern SR, Sellars WA, Johnson RB, Anderson DW, Saperstein S, Reisch JS. Development of childhood allergy in infants fed breast, soy, or cow milk. J Allergy Clin Immunol. 1973;51(3):139-151.

46. Start time of egg protein to prevent egg allergy. https://www.anzctr.org.au/Trial /Registration/TrialReview.aspx?id=335455. Accessed July 14, 2016. 